\title{
THE EFFECTS OF PERCEIVED COMPETENCE AND SELF-CONTROLLED GOAL SETTING ON MOTOR LEARNING
}

original paper

(1) University School of Physical Education in Wroclaw

DOI: https://doi.org/10.5114/hm.2021.103290

\section{CAROLINA KOMIYAMA DE ALMEIDA CARVALHAIS, SILVIA LETÍCIA DA SILVA, GO TANI, UMBERTO CESAR CORRÊA}

School of Physical Education and Sport, University of São Paulo, São Paulo, Brazil

\begin{abstract}
Purpose. On the basis of the assumptions that motor learning involves a process in which the learner gains competence on a task, and perceived competence is closely related to the achievement of a goal and the perception of control, this study investigated the effects of perceived competence and self-controlled goal setting on motor learning.

Methods. Sixty right-handed volunteers, both male $(n=28)$ and female $(n=32)$, with an average age of 26.35 years $( \pm 6.29)$ took part in this experiment. The motor learning task was the field tennis forehand stroke. The experiment involved 2 phases: acquisition and transfer. The acquisition phase consisted of 180 trials performed across 3 days. The transfer test comprised 10 trials under a modified ball flight velocity condition. The participants were divided into 3 groups depending on the level of perceived competence (high, moderate, and low). Furthermore, each group was subdivided into choice (self-controlled goal setting) and yoked groups.

Results. Performance of the high perceived competence group was superior to that in the low perceived competence group; there was no significant increase in the perception of competence in both groups. Learning was similar for self-controlled and yoked groups.

Conclusions. The findings allow us to conclude that the higher the perceived competence, the better the performance in the acquisition and transfer. Moreover, the control on goal setting did not provide an additional positive effect on motor skill learning in individuals of different levels of perceived competence.
\end{abstract}

Key words: motor skill acquisition, field tennis, motivation, self-control, forehand

\section{Introduction}

Motivation is an essential phenomenon for a variety of dimensions of human life [1]. It refers to the internal state or condition that activates or energizes someone's behaviour toward a goal [2]. In the last few years, perceived competence has been highlighted as an important motivational variable, mainly for phenomena related to the engagement in physical activity and sports [3-5]. Perceived competence is a motivational component defined as a multidimensional construct that indicates how competent an individual feels to be in relation to the cognitive, social, emotional, and/or physical aspects of their life [6]. It has also been related to the individuals' ability to be proficient on a large array of motor skills [7-9].
The point here is that the ability to perform motor skills efficiently is a learned ability, that is, it results from practice [10]. Although the relationship between motor skill learning and motivation is believed to be reciprocal since an individual can learn as a result of their motivation for the task and can also be motivated from practice [3], motor learning is a phenomenon still not much investigated with regard to perceived competence [e.g. 11, 12].

Perceived competence derives from the concept of effectance motivation, which means something that leads the individual to the search for competence and the satisfaction gained with the feeling of efficacy when the goal is reached [13]. In addition to this concept, studies on perception of competence have been influenced by 2 theories, which have in common the as-

Correspondence address: Carolina Komiyama de Almeida Carvalhais, Motor Behavior Laboratory, University of São Paulo, Av. Mello Moraes, 65, Cidade Universitária, São Paulo, SP, Brazil, CEP 05508-030, e-mail: umbertoc@usp.br

Received: November 25, 2019

Accepted for publication: July 27, 2020

Citation: Carvalhais CKA, da Silva SL, Tani G, Corrêa UC. The effects of perceived competence and self-controlled goal setting on motor learning. Hum Mov. 2021;22(4):56-67; doi: https://doi.org/10.5114/hm.2021.103290. 
sumption of the feelings of competence as an important motivational aspect that affects the performance and learning. They are the theories of self-determination [14] and motivation for competence [6].

On the one hand, Deci and Ryan's theory postulates that changes in feelings of competence and perceived autonomy produce changes in intrinsic motivation. The self-determination theory considers 3 basic psychological needs that directly influence the intrinsic motivation: autonomy, competence, and social bond. These psychological needs would lead individuals to seek and find great challenges that would result in the development of self [14].

On the other hand, Harter's theory suggests that individuals would be motivated in achievement domains in which their competence could be demonstrated. For example, in the physical domain, perceived competence would describe how competent individuals would feel in physical terms (e.g. performing motor skills). With this background, self-control and goal setting are predicted to have an important role. For instance, individuals would feel intrinsically oriented physically if they see themselves as controllers of their actions and behaviours [6]. Moreover, the manner of how people feel would affect the way they reach their set goal. In other words, to feel competent would mean to be motivated to achieve the goal [15].

In general, independently of the theoretical perspective, studies have pointed out that individuals' perceived competence increases as they reach the set goal for a motor task, that is, after good or correct performance [e.g. 11, 12, 16]. However, notwithstanding the advances in scientific development provided by the above-mentioned studies, they are not without their criticism. For instance, research has not adequately considered the perceived competence in relation to the learning process. This is because if one wants to understand the perceived competence in motor learning, it is important that it be accessed at least in 3 moments: prior to or at the beginning of practice, after or at the end of practice, and in retention and/or transfer tests. These procedures would allow verifying if and how perceived competence was affected by the practice, and also how retained and/or generalizable it was. As is well known, retention and transfer function to separate the temporary effects of performance from those that contribute to permanent learning $[10,17]$. For instance, some studies verified the individuals' perceived competence only at the end of practice [1, 11, 12]; only one study [16] investigated perceived competence before and at the end of practice. However, none of these studies evaluated perceived competence in relation to performance in the retention or transfer tests.

In this context, the present study sought to extend the existing findings by investigating perceived competence and motor skill learning. For this purpose, in addition to conducting a learning test, we manipulated the self-controlled goal setting. This is based on 2 main rationales: (i) perceived competence is closely related to the achievement of a set goal; the feeling of competence motivates the individual to reach the set goal and, consequently, the achievement of the goal increases the feeling of competence [15]; (ii) perceived competence is also related to the perception of control [6]. On this concern, studies have shown that when learners have control of some aspect of their learning, e.g. feedback (self-controlled learning), they demonstrate greater perceived competence and self-efficacy than those whose learning is controlled in totum by an experimenter [e.g. 12, 18]. In sum, besides being important to the learning process by providing a performance standard to be achieved through practice, goal setting has been recognized as a motivational strategy that benefits motor learning through self-control [e.g. 6, 19].

We hypothesized that (a) perceived competence would influence motor learning, that is, the higher the perceived competence, the better the performance in the learning test [7-9]; (b) motor learning would lead to changes in perceived competence, i.e., as a learner gained mastery on a task, they would feel more and more competent [12]; (c) having control of a task (selfcontrolled goal setting) would result in higher perceived competence than not having control $[11,16]$; and (d) having control of a task would make better performance possible in the learning test than not having control, regardless of the level of perceived competence [12].

\section{Material and method}

\section{Participants}

The participants were all those who volunteered, students of the last grade of high school, as well as workers of the State Prof. Hadla Feres School, located in the city of Carapicuiba, Brazil. The group comprised 60 right-handed subjects, both male $(n=28)$ and female $(n=32)$, with an average age of 26.35 years ( \pm 6.29). The inclusion criteria were no involvement with a systematic practice of tennis and no experience with the practice of any other racket sport. 


\section{Task and materials}

The learning task consisted of performing the forehand stroke of the sport of field tennis. The task goal was to hit a circular target (5.5 m of diameter) positioned at the bottom of the opponent's court, opposite to the learner (Figure 1). For this study, we used the motor skill of forehand stroke, open stance, with the eastern forehand grip.

A Tennis Tutor Plus Player machine allowed for the control of ball release, interval between trials, and launch velocity. The other equipment used included: (a) a Head TiS5 Comfort Zone field tennis racket; (b) 40 tennis balls of the Babolat brand; (c) 3 video cameras Casio model HS EX-FH100. As illustrated in Figure 1, 2 cameras were positioned far from $2 \mathrm{~m}$ on the right side of the participant. The cameras positions formed an angle of $45^{\circ}$ with the participant as a vertex. The height of the cameras varied depending on the participant's height $( \pm 1.5 \mathrm{~m})$. These cameras were used to capture the movement pattern, as well as the racket kinematic measures. The third camera was fixed at $3 \mathrm{~m}$ from the target in order to capture the ball contact in relation to it. We also used (d) a computer to present a model for the learner (a video with an expert performing the task); and (e) a circular target with a 5.5-m diameter.

\section{Design and procedures}

The experiment involved 2 phases: acquisition and transfer. The acquisition phase was held over 3 consecutive days. On each day, the participants performed 3 blocks of 20 trials. The interval between the trials was of 5 seconds and the interval between blocks was 3 minutes. In order to access the learning, a transfer test was run 10 minutes after the end of the last session. This is one of the oldest learning tests, which implies accessing the learning robustness or its generalization through modifying the task or situation previously practised [20]. For this purpose, in order to establish an adequate value for the ball velocity, a range of values below and above that of the acquisition phase $(50 \mathrm{~km} / \mathrm{h})$ were previously tested in a set of pilot studies. From them, $55 \mathrm{~km} / \mathrm{h}$ proved to be a velocity that implied a change in performance, but at the same time, it was feasible. Therefore, the transfer test involved 10 trials under a modified ball velocity increased from $50 \mathrm{~km} / \mathrm{h}$ (acquisition phase) to $55 \mathrm{~km} / \mathrm{h}$.

In order to verify the participant's perceived competence over the learning process, they completed a questionnaire at the beginning and end of the acquisition phase, and at the end of the transfer test. The instrument used was the Brazilian version [21] of the

\section{Camera 2}

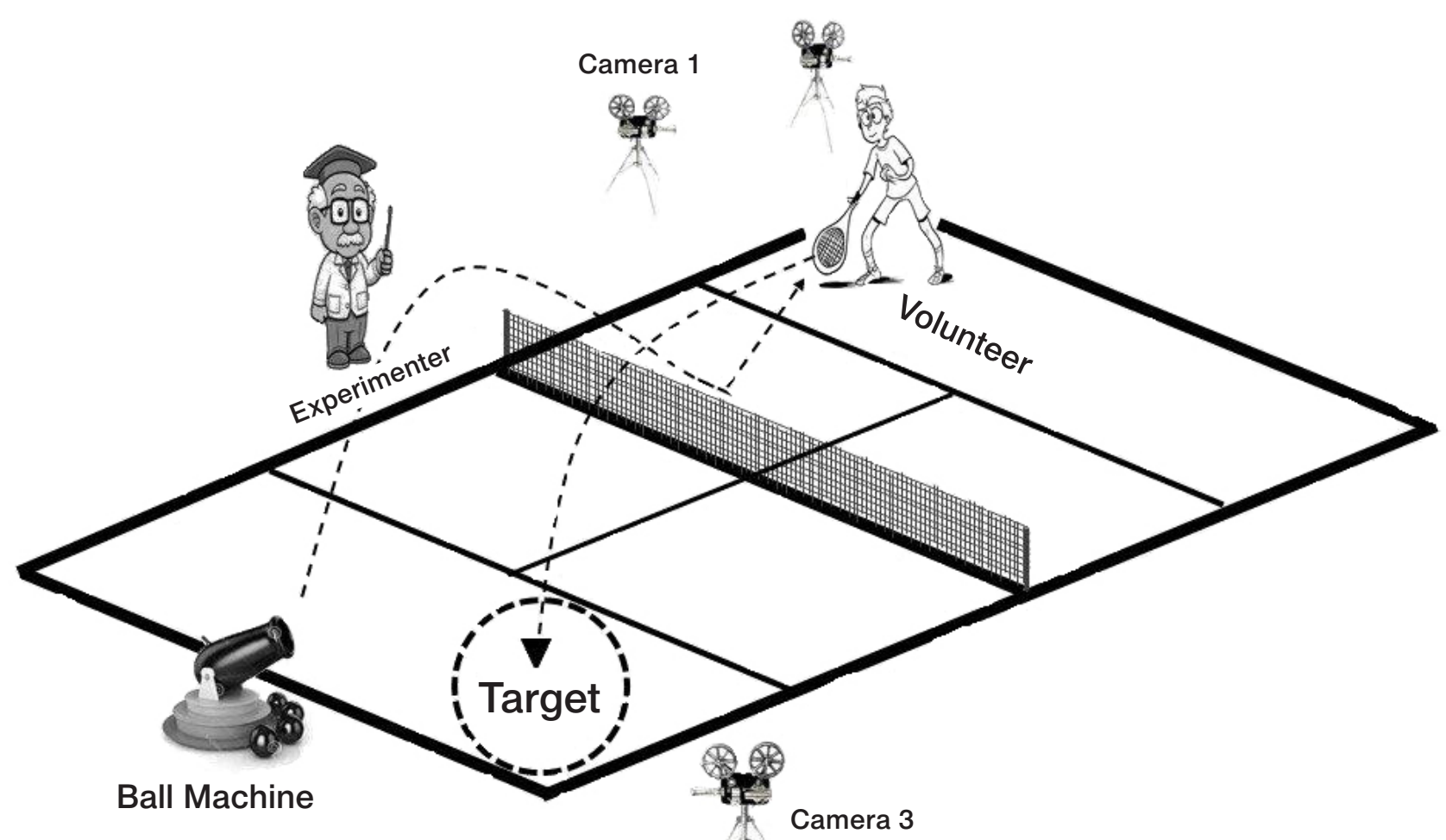

Figure 1. Illustration of the data collection experimental environment 
Physical Self-Perception Profile (PSPP) [22]. This is a widely used instrument [e.g. 23-28] that comprises 30 statements for 5 subscales: sports competence, physical condition, physical strength, body attractiveness, and physical self-worth. Each subscale contains 6 statements and each statement is composed of 2 parts: one positive and one negative. The participants read the statement and pointed out the part identified with themselves. The responses involved a score that could vary between 1 and 4 points. The scores for each subscale ranged from 6 to 24 points and the entire survey scores ranged from 30 to 120 points.

This procedure allowed us to divide the participants into 3 groups of different levels of perceived competence $(n=20)$ : high (H, score of $85-120$ points), moderate (M, score of 55-85 points), and low (L, score of 30-55 points). Furthermore, each group was randomly subdivided into choice $(\mathrm{C})$ and yoked $(\mathrm{Y})$ groups. The choice groups set their own goal for the number of target hits, while the yoked groups had the same target as set by the choice group in a paired way. The choice and yoked groups had no access to each other's procedures. The choice groups set their goals before the beginning of the second and third acquisition day. In total, the experiment involved 6 groups that combined the level of perceived competence and goal setting: HC, HY, MC, MY, LC, and LY.

Prior to the acquisition, the participants received general instructions about the forehand open stance, and were told by the experimenter: 'You must try to hit that circular target on the opponent's court. For this end, the left foot must be positioned ahead and the left arm must be positioned at the front of the body to maintain balance; the racket must be positioned above head height and the support must be on the right foot. The racket should be driven back accompanied by a rotation of the hip, and forward to beat the ball; in parallel, the left arm moves back to facilitate the rotation of the hip; after the contact with the ball, the racket ends on the left side; the left hand holds the racket to bring it to the starting position'.

The verbal instructions were accompanied by watching a video of 40 seconds of an expert performing the forehand stroke with an open stance in slow and regular velocity. Then, the participants were positioned on the court in the specific place and 4 balls were launched for familiarization with the experimental situation. This allowed the subjects to check the place where the ball fell, the velocity with which it was launched, and the best way to adjust their movement to the ball in time. These instructional procedures were repeated at the beginning of each acquisition day.

\section{Measures}

The following dependent variables were considered for the analyses:

(a) Points related to hitting the target. Two points were attributed to a hit and one point to a target error. From the points, the performance index was calculated as:

\section{$\mathrm{PI}=\Sigma \mathrm{PS} / \Sigma \mathrm{PP}$}

where PI was the performance index, PS referred to points scored, and PP stood for the points possible to be achieved. PI was calculated for the 10 first (Acq1) and 10 last (Acq8) trials of the acquisition phase, and the 10 trials of the transfer test (Tr). So, the nearer to 1 , the better the performance.

(b) Scores of movement pattern. The movement pattern was analysed by using a checklist, containing 7 items relative to the backswing ( 1 - hip should accompany the arm/racket movement back; 2 - opposite foot to the dominant arm forward; 3 - non-dominant arm forward; 4 - movement of the racket above the head line; 5 - movement of the dominant arm to back; 6 - dominant arm extended almost completely; 7 - racket to back) and 8 items relating to the forward swing (1 - hip rotation forward; 2 - non-dominant foot keep forward; 3 - non-dominant arm forward; 4 - racket movement forward in the shoulder line or slightly down; 5 - dominant arm carried forward; 6 - dominant arm extended almost completely; 7 - racket perpendicular to the ground; 8 - racket crosses the front of the body after hitting the ball) [29]. The movement pattern was evaluated by 3 experts, who agreed that these were the critical features of the movement to be considered. For each item, a score was attributed: 1.0, 0.5, or 0 if it was completely performed, partially performed, or not performed, respectively. Thus, the score for each trial varied between 0 and 15 . A correlation between raters was observed ( $r=0.93, r=0.85$, and $r=0.73$ ) [30].

(c) Kinematics of racket displacement. The amplitude and velocity of the racket in the backswing and forward swing were obtained with the SkillSpector software. This is a video-based motion analysis tool for Windows which has been recognized as useful for 3D analysis, semi-automatic scanning by using image processing techniques, advanced analysis of linear and angular kinematic data, 3D motion representation, and simple video calibration [e.g. 31]. By tracking the racket displacement trajectory, the software provided values for the $x, y$, and $z$ coordinates, and transformed them into the above measures. 
(d) Perceived competence. In addition to the variables described above, the values obtained by the participants in PSPP were also considered for analysis. The goal was to determine whether, with learning, the subjects improved their perceptions of competence. For this purpose, we considered the total score of the test, which allows evaluation of the level of perceived competence. Furthermore, we also involved the partial scores for the following components: sports competence, physical condition, body attractiveness, physical strength, and physical self-worth. The purpose of PSPP 18 is not only to verify the change in total scores of perceived competence, but also to detect the scale component in which such modification occurred. The measurements of both total and partial perceived competences are important because the learning of motor skill is not limited to acquisition of a specific sportive technique (e.g. forehand stroke of the sport of field tennis). Motor skill refers to a multidimensional phenomenon similar to the perceived competence. The skilful behaviour implies, also, the ability to perform specific techniques to the sportive context (sports competence scale). But, the focused technique refers to an efficient way of body movement (see foregoing description of forehand stroke), which may imply the body attractiveness scale because such body movement has been built by the culture over the years. In addition, becoming skilful in forehand stroke performance involves acquiring the ability to control the force applied to the racket to propel the ball to the target (physical strength scale) and, in the context of field tennis, this is done repeatedly (physical condition scale).

\section{Data analysis}

Statistical analysis considered data from 3 blocks of 10 trials: the first and last block of the acquisition phase, and the transfer block. Firstly, we verified if gender or age would affect the motor learning. For this purpose, we ran a $2 \times 2$ mixed-model ANOVA for each of these factors by considering the blocks of trials as repeated measure. The distinction between higher and lower ages was based on the median split technique. Following that, a $3 \times 2 \times 3$ mixed-model ANOVA (levels of perceived competence $\times$ self-controlled goal setting $\times$ blocks) was conducted on data from the performance index, movement pattern, kinematics of racket movement, and perceived competence. The observed significant effects were followed up by using Tukey honest significant difference (HSD) posthoc tests. All analyses considered the nature of the results, the number of participants, and the proximity between mean and median values for each group. For all analyses, the level of significance was set at $\alpha=0.05$, and the Statistica 9.0 software (StatSoft Inc., Tulsa, USA) was applied.

\section{Ethical approval}

The research related to human use has complied with all the relevant national regulations and institutional policies, has followed the tenets of the Declaration of Helsinki, and has been approved by the Research Ethics Committee of the University of São Paulo under the number CAAE 01639112.0.0000.5391.

\section{Informed consent}

Informed consent has been obtained from all individuals included in this study.

\section{Results}

\section{Performance index}

A $2 \times 3$ mixed-model ANOVA (age $\times$ blocks) revealed no interaction between these factors. It only showed differences for blocks of trials $[F(2,112)=$ $30.79, p<0.01, \eta^{2}=0.36$, observed power $\left.=1.00\right]$. The Tukey HSD test pointed out that PI in Acq8 and Tr was higher than that of Acq1 ( $p=0.0001)$. For gender, a $2 \times 3$ mixed-model ANOVA (age $\times$ blocks) also revealed no interaction. It only showed differences for blocks of trials $\left[F(2,116)=34.00, p<0.01, \eta^{2}=0.37\right.$, observed power $=1.00]$ and gender $[F(1,58)=12.62$, $p<0.01, \eta^{2}=0.37$, observed power $\left.=0.94\right]$. The Tukey HSD test again indicated that PI in Acq8 and Tr was higher than that of Acq1 ( $p=0.0001)$, and that males had superior PI than females. However, it is important to highlight that they did no differ in $\operatorname{Tr}$ (Figure 2). These results indicate that age and gender did not imply different motor learning.

A $3 \times 2 \times 3$ mixed-model ANOVA (levels of perceived competence $\times$ self-controlled goal setting $\times$ blocks) revealed main effects for perceived competence $\left[F(2,54)=6.53, p<0.01, \eta^{2}=0.19\right.$, observed power $=$ $0.89]$ and the block of trials $[F(2,108)=31.13, p<0.01$, $\eta^{2}=0.36$, observed power $\left.=1.00\right]$. The Tukey HSD test showed that the H group had higher PI than the L group $(p=0.02)$. For blocks, the Tukey HSD test established that PI in Acq 8 and Tr was higher than that of Acq1 ( $p=0.0001$ and $p=0.0002$, respectively). These results indicate that all groups learned, but that the performance of the $\mathrm{H}$ group was higher than that of the $\mathrm{L}$ group in all blocks. 

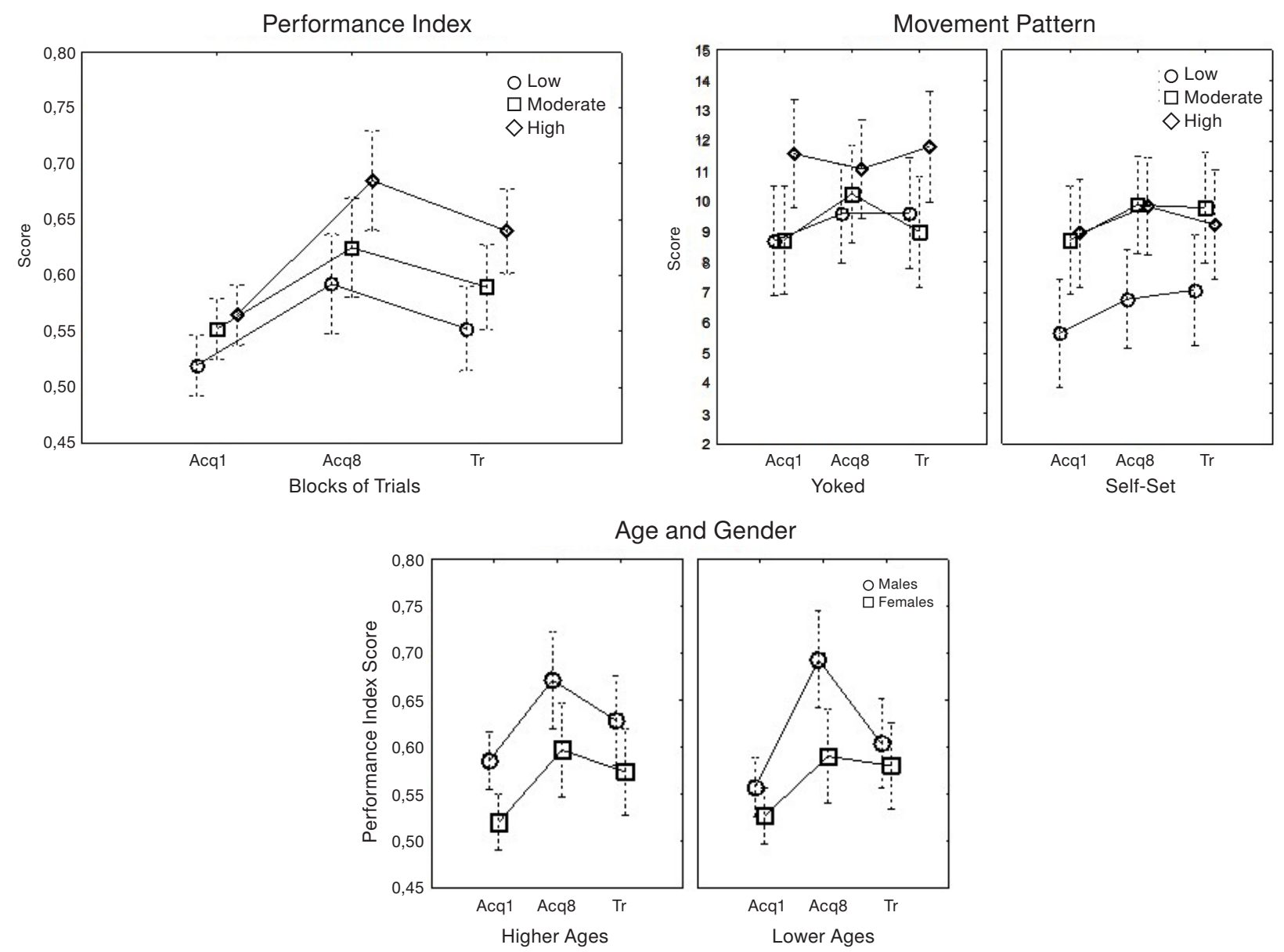

Figure 2. Means of scores of performance index and movement pattern in the groups of low, moderate, and high perceived competence, in the first (Acq1) and last (Acq8) blocks of the acquisition phase, and in the transfer test (Tr)

\section{Movement pattern}

A $3 \times 2 \times 3$ mixed-model ANOVA (levels of perceived competence $\times$ self-controlled goal setting $\times$ blocks) revealed main effects for perceived competence $\left[F(2,54)=5.17, p<0.01, \eta^{2}=0.16\right.$, observed power $=0.81]$, self-controlled goal setting $[F(1,54)=$ $6.24, p<0.05, \eta^{2}=0.10$, observed power $\left.=0.69\right]$, and blocks $\left[F(2,108)=5.73, p<0.01, \eta^{2}=0.095\right.$, observed power $=0.86]$. The post-hoc test showed that the score of movement pattern of the $\mathrm{H}$ group was superior to that of the L group ( $p=0.006)$. In addition, it was observed that the $C$ group had a more inferior score of movement pattern than the $\mathrm{Y}$ group in all blocks $(p=0.015)$. For blocks, Acq1 presented a lower score of movement than Acq8 $(p=0.005)$ and $\operatorname{Tr}(p=$ $0.027)$.

\section{Kinematics of racket displacement}

A $3 \times 2 \times 3$ mixed-model ANOVAs (levels of perceived competence $\times$ self-controlled goal setting $\times$ blocks) did not reveal effects for the amplitude or velocity of the forehand stroke.

Perceived competence - total score

A $3 \times 2 \times 3$ mixed-model ANOVA (levels of perceived competence $\times$ self-controlled goal setting $\times$ blocks) revealed main effects for perceived competence $\left[F(2,54)=67.57, p<0.001, \eta^{2}=0.71\right.$, observed power $=1.00]$ and an interaction between goal setting and blocks $\left[F(2,108)=7.01, p<0.005, \eta^{2}=0.11\right.$, observed power $=0.92]$. For perceived competence, the Tukey HSD test allowed verification that there was a hierarchy between the levels: the $\mathrm{H}$ group had higher scores than M and L ( $p=0.0001)$, and the M group had higher scores than L ( $p=0.0001)$. For goal setting and blocks, it was also established that the perception of competence in the Y group changed during the learning process, since scores in Acq 8 and Tr were higher than in Acq1 ( $p=0.01)$.

These results indicate that (a) the perception of competence in the groups differed in the learning process; 


\section{HUMAN MOVEMENT}

C. Carvalhais et al., Motivation and motor learning

(b) the yoked groups increased their scores of perceived competence during the learning process; and (c) there was no increase in the perception of competence between groups.

\section{Perceived competence - subscale scores}

Figure 3 shows the means of overall and partial scores of perceived competence. Regarding the physical strength, a $3 \times 2 \times 3$ mixed-model ANOVA (levels of perceived competence $\times$ self-controlled goal setting $\times$ blocks) revealed the following interactions: perceived competence and goal setting $[F(2,54)=3.53, p<0.005$, $\eta^{2}=0.11$, observed power $\left.=0.98\right]$, blocks and perceived competence $\left[F(4,108)=2.92, p<0.005, \eta^{2}=0.097\right.$, observed power $=0.99]$, and blocks and goal setting $\left[F(2,108)=6.36, p<0.005, \eta^{2}=0.10\right.$, observed power $=0.87]$. The post-hoc testing showed that the HY group was superior to MY ( $p=0.0001)$ and LY $(p=0.0003)$, and that the MY group was superior to LY $(p=0.032)$. It was also verified that the $H$ group was superior to $\mathrm{M}$ in all blocks and that the $\mathrm{M}$ group was superior to $\mathrm{L}$ in Acq1 $(p<0.005)$.

With reference to physical condition, a $3 \times 2 \times 3$ mixed-model ANOVA (levels of perceived competence $\times$ self-controlled goal setting $\times$ blocks) revealed an interaction between perceived competence and blocks
$\left[F(4,108)=3.16, p<0.005, \eta^{2}=0.10\right.$, observed power $=0.92]$. The Tukey HSD test pointed that the M group increased their rating from Acq1 to Acq8 $(p=0.002)$.

For sports competence, a $3 \times 2 \times 3$ mixed-model ANOVA (levels of perceived competence $\times$ self-controlled goal setting $\times$ blocks) revealed an interaction between perceived competence and self-controlled goal setting $\left[F(2,54)=3.20, p<0.005, \eta^{2}=0.10\right.$, observed power $=0.88]$. The post-hoc test showed that the scores of the HC group were superior to those in LC ( $p=$ 0.0001). It was also verified that the HY group was superior to LY ( $p=0.001)$ and MY $(p=0.0009)$, and that MY was superior to LY ( $p=0.007)$.

Regarding body attractiveness, a $3 \times 2 \times 3$ mixedmodel ANOVA (levels of perceived competence $\times$ selfcontrolled goal setting $\times$ blocks) revealed main effects only for perceived competence $[F(2,54)=22.55, p<$ $0.005, \eta^{2}=0.45$, observed power $\left.=1.00\right]$. The post-hoc testing showed that the $\mathrm{H}$ group had a superior score to $\mathrm{M}(p=0.02)$ and $\mathrm{L}(p=0.0001)$, and that the $\mathrm{M}$ group had a superior score to $\mathrm{L}(p=0.0007)$.

Finally, for physical self-worth, a $3 \times 2 \times 3$ mixedmodel ANOVA (levels of perceived competence $\times$ selfcontrolled goal setting $\times$ blocks) revealed main effects for perceived competence $[\mathrm{F}(2,54)=40.49, p<0.005$, $\eta^{2}=0.59$, observed power $\left.=0.98\right]$ and blocks $[\mathrm{F}(2,108)$ $=8.09, p<0.005, \eta^{2}=0.13$, observed power $\left.=0.87\right]$.
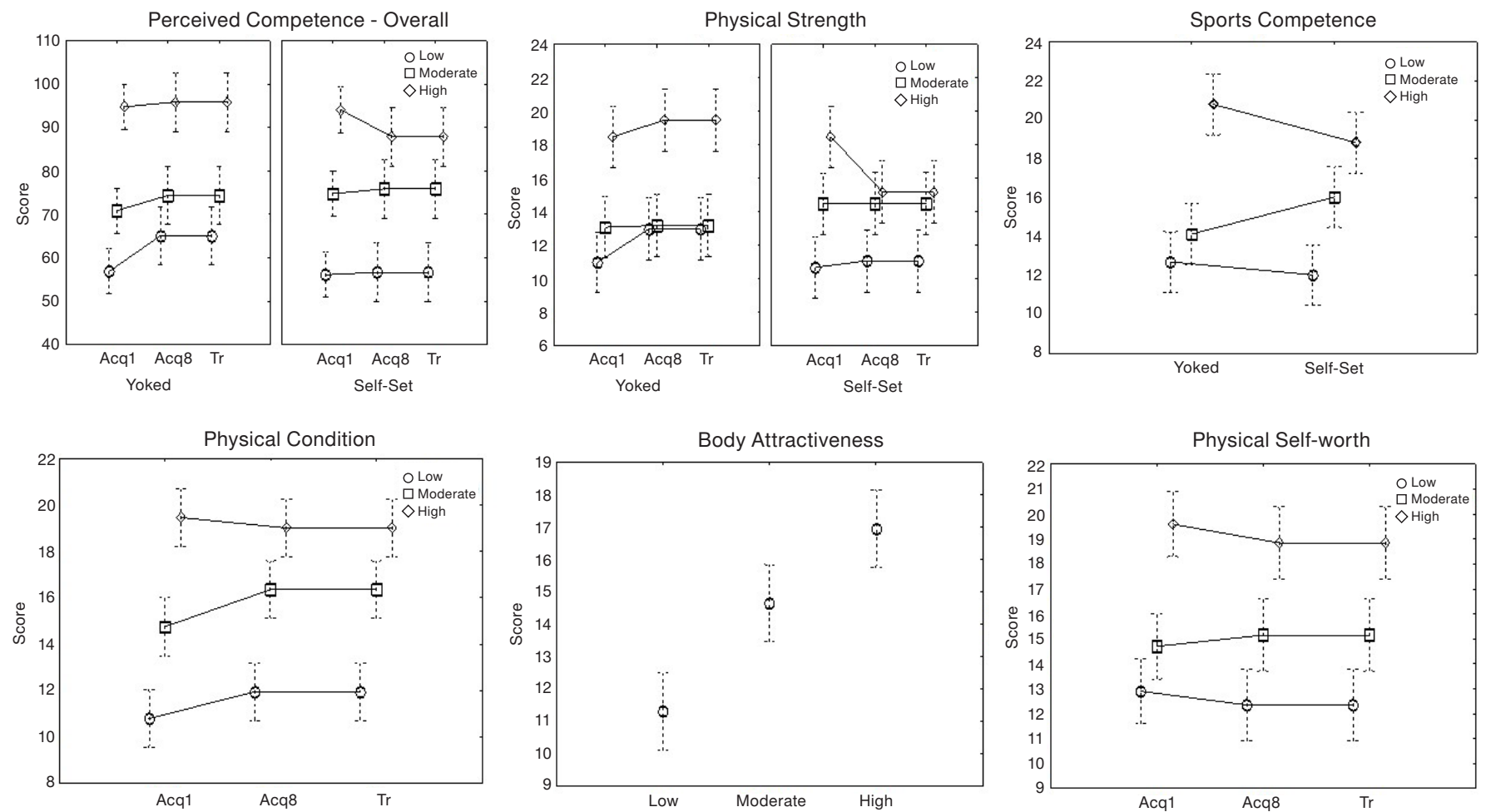

Acq1 - the first blocks of the acquisition phase, Acq8 - the last blocks of the acquisition phase, $\mathrm{Tr}$ - the transfer test

Figure 3. Means of overall and partial scores of perceived competence 
The post-hoc testing showed that the H group had a superior score to $\mathrm{M}$ and $\mathrm{L}$ ( $p=0.0001$ ), and that the scores in Acq1 were inferior to those in Acq 8 and $\mathrm{Tr}$ $(p=0.002)$.

\section{Discussion}

The aim of the study was to investigate the relationship between perceived competence and motor skills learning. Specifically, we sought to determine whether the learning of motor skills (forehand stroke in field tennis) would influence the perceived competence of the participants and if the perceived competence would affect the motor learning. Additionally, we manipulated the control on the goal setting by considering its predicted effect on those 2 variables.

First, it is important to note that individuals learned the motor skill (forehand), since all groups improved their performance index from the first to the last acquisition block. Furthermore, it was observed that learners increased the number of hits on the target and were able to adapt themselves to the change in the task. Similar results were also reported regarding the movement pattern, since the forehand scores in the last acquisition block and transfer test were superior to those in the first acquisition block.

Interestingly, although there were changes in the movement pattern, in terms of the forehand components, they were not accompanied by an alteration in kinematic characteristics (amplitude and velocity of back and forward swing). It is possible that, although learners improved their performance, this may not have occurred to the point they reached the parameterization capability. One could think that learners achieved the associative stage by becoming able to detect errors and link them to the movement pattern [32]. To put it in another way, practice can have allowed the participants to form a pattern of interaction among the key task components (e.g. arm, foot, hip, and racket movements), which resulted in the general coordination pattern of forehand stroke. However, it was not enough to provide them with the capability to assign specific values (e.g. overall duration, force, and amplitude of movement) to the formed pattern [33]. In fact, it appears that parameterization capability is not somewhat acquired quickly over the learning process.

Another interesting result is that the groups learned, but with different performance levels. In other words, throughout practice, groups of high levels of perceived competence showed better performance than groups of moderate and low levels. And, groups of moderate levels of perceived competence had better performance than groups of low levels. These findings indicate that the higher the perceived competence, the higher the performance level [12, 16, 34]. Maybe, the higher levels of perceived competence led learners to greater engagement, effort, and persistence on the task over practice as compared with the lower levels [35-38].

Furthermore, although there are no evidence-based data supporting the direct causal relationship between motor learning and perceived competence, we inductively hypothesized that the perceived competence would increase as the learning took place on the basis of the assumption that motor learning involved a process in which the learner gained competence on a task [35], However, once again, the results did not provide support for our hypothesis in the analysis of either overall or partial (component) scores. This allows us to say that in the process of learning, the individuals did not change their perceived competence. Below, we present 4 explanatory hypotheses on why this happens.

First, as previously described, the perceived competence is a multidimensional motivational phenomenon [6, 36, 37]. Therefore, not only gaining proficiency, but also other interacting factors could be responsible for modifying perceived competence. For instance, perceived competence involves the self-efficacy and selfconcept components as cognitive and affective modes, respectively, that individuals deal with [38]. Furthermore, different temporal dimensions have been proposed for these components, that is, while self-concept is most influenced by previous experiences, self-efficacy perception is related to the confidence in completing immediate tasks [38].

Second, although the learners participated freely and spontaneously in the experiment, it is possible that field tennis was not the sport (or the type of sport) they had an affinity for. This could have negatively influenced the effects of the practice on the perceived competence, since judgment of the capability to perform a motor skill has been proposed to be specific to the task or context [37-40].

Third, would perceived competence be a trait or be more influenced by the self-concept, which is fairly stable and enduring [39]? Perhaps it is no coincidence that most motor skills that perceived competence studies have focused on are fundamental (e.g. leaping, throwing, catching, jumping skills) [8, 41, 42]. These are the motor skills that form the base underpinning the cultural motor skills (e.g. sports and dances) [43]. Although both fundamental and cultural motor skills are acquired behaviours, it has been suggested that the former bring a comparatively greater phylogenetic dimension [44]. However, as a trait, perceived compe- 
tence would function similarly for one and the other. For instance, Forsman et al. [4] showed that players' levels of perceived competence, tactical skills, motivation, technical skills, and speed and agility characteristics remained stable over one year. In sum, perceived competence may be critical for the development of some motor skill performance dimensions (e.g. fitness and physical activity participation), but it cannot be modified by them [4].

Fourth, we suppose that, although learning did occur, the level of proficiency reached in the performance of the forehand stroke was not enough to cause changes in the level of perceived competence. For example, the results showed that the groups of moderate and low levels of perceived competence reached the average performance index of 0.63 and 0.59 , respectively, at the end of practice. In the present study, the performance index of 1 represented the optimal level of proficiency, i.e. a skilful behaviour. Considering that levels of skill and perceived competence are highly related [29], it is possible that much more practice would be need to change the latter. The forehand can represent a sub-facet of a hierarchical model of physical self-esteem (the subjective evaluation a person makes about themselves as intrinsically positive or negative to some degree; it encompasses beliefs about oneself) that needs to be extensively modified to influence the subdomain of perceived competence [45]. These explanatory hypotheses require future studies.

Concerning the goal setting, we based our hypothesis on the assumptions that (a) the way individuals feel about themselves would influence their relationship to goal setting [15]; and (b) they would feel intrinsically motivated if they saw themselves as controllers of their actions and behaviours [6]. In fact, similar to the case of high levels of perceived competence, selfcontrolled goal setting has been seen as a motivational aspect that promotes an increase in the active involvement in the process, feelings of self-efficacy, and, therefore, intrinsic motivation, perception of self, commitment, effort, persistence, and participation [19, 46]. On this basis, we hypothesized that the self-control of goal setting would result in higher learning and perceived competence than external goal setting. However, contrary to our expectation, the results showed that the yoked groups obtained better movement patterns and increased perceived competence more than the self-controlled goal setting groups. We consider 5 possible explanations.

First, although the learners were engaged in setting their own goals, this result may have occurred because they were beginners and did not have the nec- essary competence to enjoy self-control [18], or they were not able to set sufficiently challenging goals to the point of bringing about the benefits of self-control [47].

Second, instruction may have decreased the perceived autonomy in the self-controlled goal setting groups. This is because some words used in the instruction may have directed the learners' attention more to constraints or obligations, that is, to what they had to do, rather than to freedom of choice in the practice. For instance, we used such commands as 'you must try...,' 'the left foot must...,' 'the arm must...,' 'the racket should.... Thus, the instructional language that we applied may have had an effect of control instead of autonomy support or neutral motor learning [48].

Third, the externally set goal may have motivated the learners by directing their attention to a specific pattern and, therefore, a reference to be reached over practice $[49,50]$.

Fourth, the subjects in the yoked condition may not have committed to the externally set goal by setting their own one. This would imply the same learning benefits compared with the self-controlled goal setting group [51, 52]. For instance, Marques et al. [19] investigated the impact of a priori and a posteriori self-goal setting on motor skill learning. In this case, within the yoked group, another group was formed by considering those participants who, even with a goal externally set, self-set their own one. The results showed better motor learning in both self-goal setting groups as compared with the yoked group.

Fifth, perceived competence may not interact accordingly with the self-control of other learning motivational variables. For example, the motivational function of feedback has been the focus of recent studies on self-controlled motor learning $[1,53]$. Also, Barros et al. [54] investigated the effects of self-controlled feedback on motor learning considering the yoked participants' error estimation. They found better learning in the yoked group than in the self-controlled one. Therefore, the expected benefit effects of self-controlled feedback did not occur. These explanatory hypotheses also need to be verified in further studies.

\section{Conclusions}

In summary, the findings of this study allow us to conclude that the higher the perceived competence, the better the performance in the acquisition and transfer. However, the opposite did not occur, i.e., motor learning did not affect the perceived competence. Finally, the control over goal setting, i.e. self-controlled goal setting, did not provide an additional positive ef- 
fect on motor skill learning in individuals of different levels of perceived competence. These results, in addition to their contribution to the advance of knowledge about the interaction among perceived competence, goal setting, and motor learning, can still inspire useful insights into the design of practice tasks. In this sense, teachers and coaches could promote the practice of the forehand stroke of the sport of field tennis regardless of who sets the goals and of the learners' level of perceived competence. Importantly, these conclusions are closely related to the methods and findings of the present study. Most of the findings are based on low to moderate effect sizes, but with high observed power. The results of the power analysis suggest that the analyses were effective in detecting the differences that actually existed. In turn, not so large effect sizes imply that the dependent variable may have been influenced by other variables, such as the group division. In this case, the main implication is on the generalization power as a possible study limitation. Thus, replication is needed to achieve the necessary consistency for generalization. Another limitation that should be considered in further studies is the control of the selfgoal setting in the yoked group.

\section{Acknowledgments}

This research was supported by the CAPES Foundation, Ministry of Education of Brazil; the support was awarded to the first author.

\section{Disclosure statement}

No author has any financial interest or received any financial benefit from this research.

\section{Conflict of interest}

The authors state no conflict of interest.

\section{References}

1. Lewthwaite R, Wulf G. Motor learning through a motivational lens. In: Hodges NJ, Williams AM (eds.), Skill acquisition in sport: research, theory, and practice, $2^{\text {nd }}$ ed. London: Routledge; 2012; 173-191.

2. Kleinginna PR Jr, Kleinginna AM. A categorized list of motivation definitions, with a suggestion for a consensual definition. Motiv Emot. 1981;5(3):263-291; doi: 10.1007/BF00993889.

3. De Meester A, Maes J, Stodden D, Cardon G, Goodway J, Lenoir M, et al. Identifying profiles of actual and perceived motor competence among adolescents: associations with motivation, physical activity, and sports participation. J Sports Sci. 2016;34(21):20272037; doi: 10.1080/02640414.2016.1149608.
4. Forsman H, Gråstén A, Blomqvist M, Davids K, Liukkonen J, Konttinen N. Development of perceived competence, tactical skills, motivation, technical skills, and speed and agility in young soccer players. J Sports Sci. 2016;34(14):1311-1318; doi: 10.1080/02640414. 2015.1127401

5. Hamari L, Heinonen OJ, Aromaa M, Asanti R, Koivusilta L, Koski P, et al. Association of self-perceived physical competence and leisure-time physical activity in childhood - a follow-up study. J Sch Health. 2017;87(4):236-243; doi: 10.1111/josh.12490.

6. Harter S. Effectance motivation reconsidered: toward a developmental model. Hum Dev. 1978;21(1):34-64; doi: 10.1159/000271574.

7. Stodden DF, Goodway JD, Langendorfer SJ, Roberton MA, Rudisill ME, Garcia C, et al. A developmental perspective on the role of motor skill competence in physical activity: an emergent relationship. Quest. 2008; 60(2):290-306;doi:10.1080/00336297.2008.10483582.

8. Jaakkola T, Huhtiniemi M, Salin K, Seppälä S, Lahti J, Hakonen H, et al. Motor competence, perceived physical competence, physical fitness, and physical activity within Finnish children. Scand J Med Sci Sports. 2019;29(7):1013-1021; doi: 10.1111/sms.13412.

9. Hands B, Parker HE, Rose E, Larkin D. Gender and motor competence affects perceived likelihood and importance of physical activity outcomes among 14 year olds. Child Care Health Dev. 2016;42(2):246-252; doi: 10.1111/cch.12298.

10. Magill RA. Motor learning: concepts and applications [in Portuguese]. São Paulo: Blucher; 2000.

11. Ávila LTG, Chiviacowsky S, Wulf G, Lewthwaite R. Positive social-comparative feedback enhances motor learning in children. Psychol Sport Exerc. 2012;13(6): 849-853; doi: 10.1016/j.psychsport.2012.07.001.

12. Chiviacowsky S, Wulf G, Lewthwaite R. Self-controlled learning: the importance of protecting perceptions of competence. Front Psychol. 2012;3:458; doi: 10.3389/fpsyg.2012.00458.

13. White RW. Motivation reconsidered: the concept of competence. Psychol Rev. 1959;66(5):297-333; doi: 10.1037/h0040934.

14. Deci EL, Ryan RM. Intrinsic motivation and self-determination in human behavior. New York: Plenum Press; 1985.

15. Biddle SJH. Cognitive theories of motivation and the physical self. In: Fox KR (ed.), The physical self: from motivation to well-being. Champaign: Human Kinetics; 1997; 59-82.

16. Li W, Lee AM, Solmon MA. Relationships among dispositional ability conceptions, intrinsic motivation, perceived competence, experience, persistence, and performance. J Teach Phys Educ. 2005;24(1):51-65; doi: 10.1123/jtpe.24.1.51.

17. Schmidt RA, Lee TD. Motor control and learning: a behavioral emphasis, $5^{\text {th }}$ ed. Champaign: Human Kinetics; 2011. 
18. Marques PG, Corrêa UC. The effect of learner's control of self-observation strategies on learning of front crawl. Acta Psychol. 2016;164:151-156; doi: 10.1016/j.actpsy.2016.01.006.

19. Marques PG, Walter C, Tani G, Corrêa UC. The effect of self-goal setting on the acquisition of a motor skill [in Portuguese]. Motricidade. 2014;10(4):56-63; doi: 10.6063/motricidade.10(4).2981.

20. Schmidt RA, Lee TD, Winstein CJ, Wulf G, Zelaznik HN. Motor control and learning: a behavioral emphasis, $6^{\text {th }}$ ed. Champaign: Human Kinetics; 2018.

21. Ferreira JP, Rocha DN, Furtado GE, Benevides VM. Brazilian adaptation of the Physical Self-Perception Profile (PSPP): adult version [in Portuguese]. Coimbra: Universidade de Coimbra; 2008.

22. Fox KR, Corbin CB. The physical self-perception profile: development and preliminary validation. J Sport Exerc Psychol. 1989;11(1):408-430; doi: 10.1123/jsep. 11.4.408.

23. Aşçi FH, Aşçi A, Zorba E. Cross-cultural validity and reliability of Physical Self-Perception Profile. Int J Sport Psychol. 1999;30(3):399-406.

24. Ferreira JP, Teixeira AM, Massart AG, Filaire E. Assessing self-esteem and perceived physical competence in elderly using the Physical Self-Perception Profile. Eur J Adapt Phys Act. 2013;6(2):7-18; doi: 10.5507/euj. 2013.006.

25. Kalaja S, Jaakkola T, Watt A, Liukkonen J, Ommundsen Y. The associations between seventh grade Finnish students' motivational climate, perceived competence, self-determined motivation, and fundamental movement skills. Eur Phys Educ Rev. 2009;15(3):315335; doi: 10.1177/1356336X09364714.

26. Lindwall M, Hassmén P. The role of exercise and gender for physical self-perceptions and importance ratings in Swedish university students. Scand J Med Sci Sports. 2004;14(6):373-380; doi: 10.1046/j.1600-0838. 2003.372.x.

27. Özdemir RA, Çelik Ö, Aşçı FH. Exercise interventions and their effects on physical self-perceptions of male university students. Int J Psychol. 2010;45(3):174-181; doi: 10.1080/00207590903473750.

28. Thornton J, Kato K. Physical self-perception profile of female college students: kinesiology majors vs. non-kinesiology majors. Sport J. 2012. Available from: https:// thesportjournal.org/article/physical-self-perceptionprofile-of-female-college-students-kinesiology-majors-vs-non-kinesiology-majors/.

29. Grabb J. Fully prepared. Tennis. 2003;5:70-71.

30. Levin J, Fox JA. Statistics for the social sciences [in Portuguese], $9^{\text {th }}$ ed. São Paulo: Pearson; 2004.

31. Sinclar PJ, Walker CA, Rickards T. Kinematic determinants of dive height in springboard diving. Mov Sports Sci. 2012;75(1):107-112; doi: 10.1051/SM/2011161.

32. Fitts PM, Posner MI. Human performance. Belmont: Brooks/Cole; 1967.
33. Denardi RA, Corrêa UC. Effects of instructional focus on learning a classical ballet movement, the pirouette. J Dance Med Sci. 2013;17(1):18-23; doi: 10.12678/ 1089-313X.17.1.18.

34. Allen JB, Howe BL. Player ability, coach feedback, and female adolescent athletes' perceived competence and satisfaction. J Sport Exerc Psychol. 1998;20(3):280-299.

35. Marsh HW, Sonstroem RJ. Importance ratings and specific components of physical self-concept: relevance to predicting global components of self-concept and exercise. J Sport Exerc Psychol. 1995;17(1):84-104; doi: 10.1123/jsep.17.1.84.

36. Barnett LM, Vazou S, Abbott G, Bowe SJ, Robinson LE, Ridgers ND, et al. Construct validity of the pictorial scale of Perceived Movement Skill Competence. Psychol Sport Exerc. 2016;22:294-302; doi: 10.1016/j.psychsport.2015.09.002.

37. Estevan I, Barnett LM. Considerations related to the definition, measurement and analysis of perceived motor competence. Sports Med. 2018;48(12):2685-2694; doi: 10.1007/s40279-018-0940-2.

38. Ommundsen Y. Implicit theories of ability and self-regulation strategies in physical education classes. Educ Psychol. 2003;23(2):141-157; doi: 10.1080/01443410 303224.

39. Hughes A, Galbraith D, White D. Perceived competence: a common core for self-efficacy and self-concept? J Pers Assess. 2011;93(3):278-289; doi: 10.1080/0022 3891.2011.559390.

40. Bandura A. Self-efficacy: the exercise of control. New York: Freeman; 1997.

41. Robinson LE, Stodden DF, Barnett LM, Lopes VP, Logan SW, Rodrigues LP, et al. Motor competence and its effect on positive developmental trajectories of health. Sports Med. 2015;45(9):1273-1284; doi: 10.1007/ s40279-015-0351-6.

42. Barnett LM, Stodden D, Cohen KE, Smith JJ, Lubans DR, Lenoir M, et al. Fundamental movement skills: an important focus. J Teach Phys Educ. 2016;35(3): 219-225; doi: 10.1123/jtpe.2014-0209.

43. Haywood KM, Getchell N. Life span motor development. Champaign: Human Kinetics; 2014.

44. Payne VG, Isaacs LD. Human motor development: a lifespan approach. New York: McGraw-Hill; 2011.

45. Sonstroem RJ, Morgan WP. Exercise and self-esteem: rationale and model. Med Sci Sports Exerc. 1989;21(3): 329-337; doi: 10.1249/00005768-198906000-00018.

46. Boyce BA, Bingham SM. The effects of self-efficacy and goal setting on bowling performance. J Teach Phys Educ. 1997;16(3):312-323; doi: 10.1123/jtpe.16.3.312.

47. Corrêa UC, de Souza OP Jr. Effects of goal difficulty and temporality in motor skill acquisition using the Bachman ladder. Percept Mot Skills. 2009;109(3):817823; doi: 10.2466/pms.109.3.817-823.

48. Hooyman A, Wulf G, Lewthwaite R. Impacts of autonomy-supportive versus controlling instructional lan- 
guage on motor learning. Hum Mov Sci. 2014;36:190198; doi: 10.1016/j.humov.2014.04.005.

49. Locke EA, Latham GP. The application of goal setting to sports. J Sport Psychol. 1985;7(3):205-222; doi: 10.1123/ jsp.7.3.205.

50. Mooney RP, Mutrie N. The effects of goal specificity and goal difficulty on the performance of badminton skills in children. Pediatr Exerc Sci. 2000;12(3):270283; doi: 10.1123/pes.12.3.270.

51. Neiva JFO, Araújo UO, Ugrinowitsch H, Corrêa UC. Effect of self-controlled goal setting on motor learning [in Portuguese]. In: Tani G (ed.), Motor behaviour: concepts, studies, and applications [in Portuguese]. Rio de Janeiro: Guanabara Koogan; 2016; 85-88.

52. Walter C, Bastos FH, Araújo UO, Tani G. Study of selfcontrolled motor learning: fundamentals and perspectives [in Portuguese]. In: Tani G (ed.), Motor behaviour: concepts, studies, and applications [in Portuguese]. Rio de Janeiro: Guanabara Koogan; 2016; 17-23.

53. Drews R, Pacheco MM, Bastos FH, Tani G. Knowledge of results do not affect self-efficacy and skill acquisition on an anticipatory timing task. J Mot Behav. 2021;53(3): 275-286; doi: 10.1080/00222895.2020.1772711.

54. Barros JAC, Yantha ZD, Carter MJ, Hussien J, SteMarie DM. Examining the impact of error estimation on the effects of self-controlled feedback. Hum Mov Sci. 2019;63:182-198; doi: 10.1016/j.humov.2018.12.002. 